\title{
REORGANIZATION ENERGIES FOR CHARGE TRANSFER IN CARBAZOLE COMPOUND CONTAINING TRINITROFLUORENONE
}

\author{
G. Vektaris ${ }^{a}$ and A. Vektariené ${ }^{\mathrm{a}, \mathrm{b}}$ \\ ${ }^{a}$ Institute of Theoretical Physics and Astronomy of Vilnius University, A. Goštauto 12, LT-01108 Vilnius, Lithuania \\ E-mail: vektaris@itpa.lt \\ ${ }^{\mathrm{b}}$ Institute of Biochemistry, Mokslininku 12, LT-08662 Vilnius, Lithuania
}

Received 15 February 2007

\begin{abstract}
Semiempirical quantum chemical calculations were performed to estimate the reorganization energies for charge transfer process in carbazole containing compound doped with trinitrofluorenone. Geometries of carbazole and trinitrofluorenone molecules were optimized in neutral, cationic (carbazole), and anionic (trinitrofluorenone) forms. Obtained geometries were used to calculate energies of compounds in neutral and ionized forms. Nelsen's method was used to calculate internal reorganization energy of self-exchange hole transfer reaction in carbazole. Cross-reaction of electron transfer from carbazole to trinitrofluorenone was calculated using Marcus cross relation. Free energy of this reaction was calculated too. Obtained values are discussed as concerns the suitability for effective charge separation reactions in carbazole compounds.
\end{abstract}

Keywords: charge transfer, reorganization energy, quantum chemistry

PACS: $82.30 . \mathrm{Fi}, 31.15 . \mathrm{Ct}, 31.50 . \mathrm{Bc}$

\section{Introduction}

The significance of charge transfer $(\mathrm{CT})$ processes for scientific and technological progress is evident nowadays. They take place almost everywhere. Chemical reactions are accompanied by charge transfer. Biochemical processes in living cells such as photosynthesis, breathing, DNA replication, etc. involve charge transfer reactions. Technologically valuable processes, such as photocopying, are based on it too. Thus the investigation of charge transfer process by means of experimental ant theoretical techniques is of the major scientific interest today. That confirms a huge amount of papers on this subject. Nevertheless, our knowledge of charge transfer is not thorough. Up to now, it is difficult to apply direct quantum chemical calculation methods with the aim to estimate charge transfer process, due to low accuracy of those methods. So at present it is commonly accepted that charge transfer reaction is best described by Marcus theory [1] which has only a few parameters such as reorganization energy, free energy of CT reaction, and interaction matrix element. In spite of its simplicity these parameters are difficult to estimate theoretically. One of the methods to evaluate them is quantum chemical calculation.

According to Marcus theory the charge transfer may occur inside one molecule or between two separated molecules. The first case is called an inner-sphere or intramolecular charge transfer while the second is an outer-sphere or intermolecular transfer. It is commonly accepted that intramolecular CT is mostly influenced by properties of molecule in which charge transfer occurs, while surrounding molecules mainly influence the intermolecular CT. Nevertheless, both cases are dependent on properties of the charge transferring molecules and the surrounding ones.

The aim of our paper is to calculate inner reorganization energy of the CT process taking place in carbazole (Cz) compounds doped with 2,4,7-trinitrofluorenone (TNF) molecules. Such pairs of compounds are often used in photocopying devices and is a popular object for investigation of charge transfer up to now [2]. Experimentally $\mathrm{Cz}$ is investigated in its molecular form and in polymeric form such as poly-(N-vynilcarbazole) or poly-N-epoxypropylcarbazole. In the latter case it is considered that charge transfer occurs between $\mathrm{Cz}$ chromophores [3] leaving polymeric backbone inactive. So we explore only $\mathrm{Cz}$ molecule to simplify the task. It is well known that charge transfer occurs after photoexcitation of TNF [3] (see also [4]) which is a photosensitizer lowering the absorption from ultraviolet to visible light region. After photoexcitation of TNF a thermalization stage follows causing an electron 


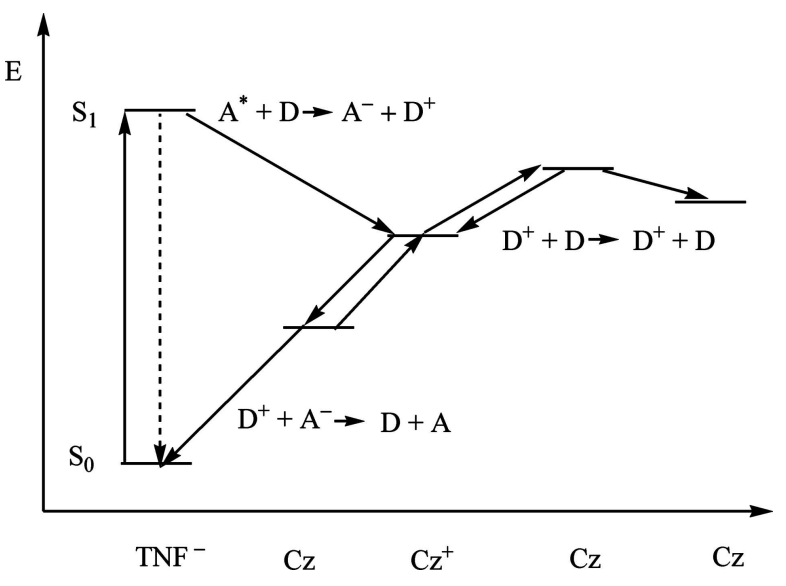

Fig. 1. Schematic representation of CT processes occurring in $\mathrm{Cz}$ compound doped with TNF after photoexcitation. $\mathrm{S}_{1}$ is photoexcited state of TNF.

transfer from $\mathrm{Cz}$ to photoexcited TNF molecule. Thus geminate charge pair is created consisting of a negative TNF molecule (electron acceptor) with excess electron and a positive $\mathrm{Cz}$ (electron donor) with deficiency of electron or with a so-called hole created on it [3]. Experimentally it is known that such hole exhibits mobility by hopping from one $\mathrm{Cz}$ molecule (chromophore) to another (see Fig. 1). If an electric field is applied to the sample, a consequence of such hopping is the charge separation or recombination in the system. If the $\mathrm{Cz}^{+}-$ $\mathrm{TNF}^{-}$pair is in high electric field, only a small amount of charge pairs recombine. Consequently, such materials are useful for photocopying devices.

The most unclear stage is thermalization. There are many theories describing it [4-7]. The separation (recombination) stage is usually described by Onsager theory [8]. It is commonly used to calculate the thermalization radii when quantum yield of separated charges is given. But the Onsager theory is based on continuous substance approximation and lacks the discrete molecular structure of material. Thermalization radii calculated in this way are very large. Another approach to charge separation is based on charge hopping model [9] suitable for discrete molecular structure and in limiting case equivalent to Onsager theory. This approach [9] complemented with thermalization theory [7] describes charge separation in a unified integral way [10] where all stages are described on the same footing using parameters of Marcus theory for charge transfer. These parameters are based on properties of constituent molecules. It also gives reasonable thermalization radii, so we rely on this theory further in our work. In paper [10] inner reorganization energy was used as a parameter of theory. Therefore our aim is to obtain the values of inner reorganization energies

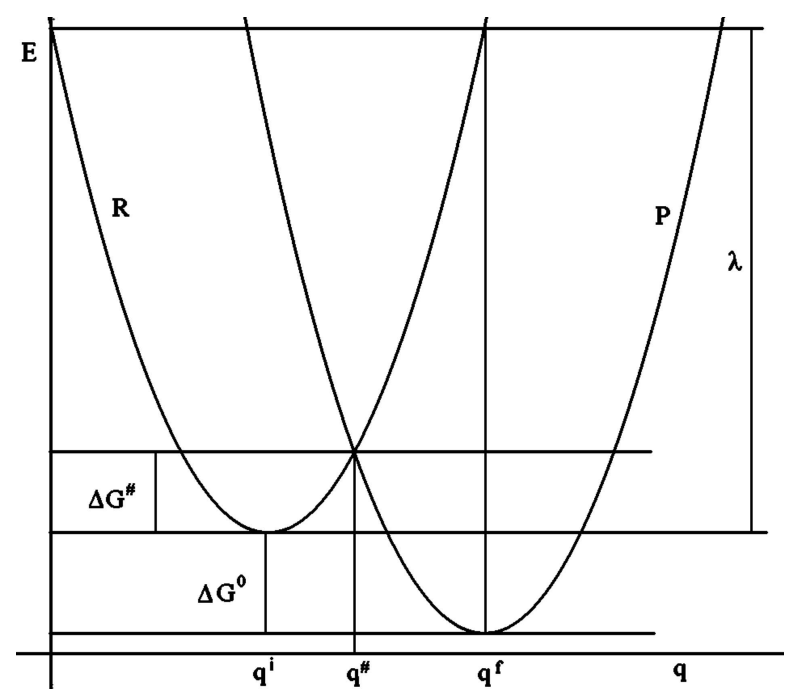

Fig. 2. Schematic representation of potential energy surfaces approximated by parabolas. $\mathrm{R}$ and $\mathrm{P}$ denote reactant and product states accordingly.

of $\mathrm{Cz}-\mathrm{TNF}$ system for all CT stages: thermalization, separation, and recombination of charges by quantum chemical calculations.

\section{Calculation methods}

According to Marcus theory [1], the charge transfer reaction happens nonadiabatically when two harmonic free energy profiles - of reactants $(\mathrm{R})$ and products $(\mathrm{P})$ - cross each other (see Fig. 2). Thus the initial harmonic potential energy of reactants may be written as

$$
U_{i}=\frac{1}{2} \sum_{n} C_{n}\left(q_{n}-q_{n}^{i}\right)^{2}
$$

where $q_{n}$ and $q_{n}^{i}$ are actual and equilibrium coordinates of reactant, $C_{n}$ are force constants. For products of CT reaction the final energy may be written as

$$
U_{f}=\Delta G^{0}+\frac{1}{2} \sum_{n} C_{n}\left(q_{n}-q_{n}^{f}\right)^{2},
$$

where the final equilibrium coordinates $q_{n}^{f}$ are different from the initial $q_{n}^{i} . \Delta G^{0}$ is free energy of CT reaction. Charge transfer occurs along the line (the so-called reaction coordinate) connecting these two minima when two potential surfaces cross at the transition state. This happens in the point with coordinates $q_{n}^{\#}$ and energy $\Delta G^{\#}$ which is called activation energy of CT reaction,

$$
\Delta G^{\#}=\frac{\left(\Delta G^{0}+\lambda\right)^{2}}{4 \lambda}
$$


where parameter $\lambda$ is reorganization energy of the system and is defined as follows (also see Fig. 2):

$$
\lambda=\frac{1}{2} \sum_{n} C_{n}\left(q_{n}^{f}-q_{n}^{i}\right)^{2} .
$$

Usually, as said in introduction, the total reorganization energy consists of two parts: $\lambda_{\mathrm{i}}$ is internal reorganization energy of charge transferring molecules and $\lambda_{\mathrm{a}}$ is reorganization energy of ambient molecules,

$$
\lambda=\lambda_{\mathrm{i}}+\lambda_{\mathrm{a}} .
$$

$\lambda_{\mathrm{a}}$ may be evaluated using Born formula [1]

$$
\lambda_{\mathrm{a}}=\frac{e^{2}}{4 \pi \varepsilon_{0}}\left(\frac{1}{2 a_{1}}+\frac{1}{2 a_{2}}-\frac{1}{r_{1,2}}\right)\left(\frac{1}{\varepsilon_{\infty}}-\frac{1}{\varepsilon_{0}}\right) .
$$

Here $a_{1}, a_{2}, r_{1,2}, \varepsilon_{\infty}$, and $\varepsilon_{0}$ respectively are the radii of the donor and acceptor, the distance between their centres, and the optical frequency and zero frequency dielectric constants of the solvent; $e$ is the amount of charge transferred.

Our task is to calculate $\lambda_{\mathrm{i}}$. Direct calculation [11] of $\lambda_{\mathrm{i}}$ using the formula (4) is possible only for very simple molecules, usually containing only a few atoms. Much more preferred method of its calculation is based on the difference of molecular energies between initial (1) and final (2) states using the so-called Nelsen method [12] (see also [13] and Fig. 2).

As already mentioned in introductory chapter, the processes considered (see Fig. 1) may be described by such a schema:

$$
\begin{aligned}
& A+\hbar \omega \rightarrow A^{*}, \\
& A^{*}+D \rightarrow A^{-}+D^{+}, \\
& D^{+}+D \rightarrow D+D^{+},
\end{aligned}
$$

where the electron acceptor ( $A$ in schema) is a TNF molecule, while the donor ( $D$ in schema) is Cz. The first stage describes photoexcitation of TNF, the second is initial charge separation (thermalization), and the last is migration of the hole through $\mathrm{Cz}$ molecules in the nearby presence of negatively charged TNF molecule. The result of such migration may be a separated electron-hole pair (usually in high electric field) or a charge recombination described by the reaction

$$
D^{+}+A^{-} \rightarrow D+A .
$$

Nelsen method [12] is well suited for the so-called selfexcange CT reactions, such as the third stage of (7), when charge migrates between two identical molecules (or chromophores). For so-called cross-reaction, when charge hops from one molecule to a molecule of another kind (the second stage of (7) reaction),

$$
A+D \rightarrow A^{-}+D^{+},
$$

the internal reorganization energy should be calculated according to Marcus cross relation $[1,14]$ as the mean of two reorganization energies for self-exchange reactions:

$$
\lambda_{\mathrm{i}}=\frac{\lambda_{A}+\lambda_{D}}{2},
$$

where $\lambda_{A}$ corresponds to reaction

$$
A^{-}+A \rightarrow A+A^{-},
$$

and $\lambda_{D}$ to

$$
D^{+}+D \rightarrow D+D^{+} .
$$

Initial state in (11) is the negative electron acceptor $A_{\mathrm{a}}^{-}$having anionic geometry and neutral acceptor having geometry of neutral molecule $A_{\mathrm{n}}^{0}$. Both geometries are equilibrium ones. The final state of this reaction is the neutral acceptor having anionic geometry $A_{\mathrm{a}}^{0}$ and negative acceptor $A_{\mathrm{n}}^{-}$with geometry of neutral molecule. Both these geometries are non-equilibrium ones, describing nonadiabatic (vertical) charge transition. According to Nelsen, the expression for internal reorganization energy may be written as energy differences of corresponding structures:

$$
\lambda_{A}=E\left(A_{\mathrm{a}}^{0}\right)+E\left(A_{\mathrm{n}}^{-}\right)-E\left(A_{\mathrm{a}}^{-}\right)-E\left(A_{\mathrm{n}}^{0}\right) .
$$

Analogously, (12) (or the third stage of (7) reaction) has the initial state with positive donor having cationic geometry $D_{\mathrm{c}}^{+}$and neutral donor with neutral structure $D_{\mathrm{n}}^{0}$. The final state of it may be characterized as the neutral donor having cationic geometry $D_{\mathrm{c}}^{0}$ and positive donor having neutral geometry $D_{\mathrm{n}}^{+}$. So the formula of internal reorganization energy may be written as follows:

$$
\lambda_{D}=E\left(D_{\mathrm{c}}^{0}\right)+E\left(D_{\mathrm{n}}^{+}\right)-E\left(D_{\mathrm{c}}^{+}\right)-E\left(D_{\mathrm{n}}^{0}\right) .
$$

Recombination stage presented by Eq. (8) is a crossreaction and should be described by (10)-(14) formulas. If Nelsen approach were valid for cross-reaction, the reorganization energy should be expressed in a following way:

$$
\lambda_{N}=E\left(D_{\mathrm{c}}^{0}\right)+E\left(A_{\mathrm{a}}^{0}\right)-E\left(D_{\mathrm{c}}^{+}\right)-E\left(A_{\mathrm{a}}^{-}\right) .
$$

Nevertheless, the expression (15) is not valid and we can see that it is missing four terms.

As we have declared, our task consists in optimization of molecular geometries for anionic, cationic, and 
Table 1. Energy values (in atomic units) for $\mathrm{Cz}$ and $\mathrm{TNF}$ with various geometric structures and charges (see text for details). Calculation methods are AM1 and PM3.

\begin{tabular}{cccc}
\hline \multirow{2}{*}{ Compound } & \multicolumn{2}{c}{ Energy } \\
\cline { 3 - 4 } $\mathrm{Cz}$ & Structure & AM1 & PM3 \\
\hline & $D_{\mathrm{n}}^{0}$ & -68.57277 & -63.27630 \\
& $D_{\mathrm{c}}^{+}$ & -68.29488 & -63.00063 \\
& $D_{\mathrm{n}}^{+}$ & -68.29214 & -62.98748 \\
& $D_{\mathrm{c}}^{0}$ & -68.56996 & -63.27177 \\
\hline $\mathrm{TNF}$ & $A_{\mathrm{n}}^{0}$ & -168.50468 & -152.49056 \\
& $A_{\mathrm{a}}^{-}$ & -168.64402 & -152.62933 \\
& $A_{\mathrm{n}}^{-}$ & -168.63692 & -152.61920 \\
& $A_{\mathrm{a}}^{0}$ & -168.49747 & -152.48050 \\
\hline
\end{tabular}

neutral structures and the calculation of energies for negative, positive, and neutral species obtained. To simplify the task, instead of calculating the geometry for excited state we will use neutral TNF molecule geometry assuming that excitation does not significantly change the geometry. Calculations were performed using GAMESS program package [15] with semiempirical AM1 and PM3 unrestricted Hartree-Fock Hamiltonian to study the CT reactions. Besides the reorganization energies for above-mentioned compounds, the other important quantities for $\mathrm{CT}$ were calculated, such as ionization potential $I_{\mathrm{g}}$ for the donor and electron affinity $A_{\mathrm{g}}$ of the acceptor. Visualization of molecular structures was performed with MOLEKEL [16].

\section{Results and discussion}

Semiempirical AM1 method was used for calculation on the assumption that it gives reliable results. Authors of [13] publication performed calculations using AM1, $a b$ initio, and density functional (DFT) methods. Their results indicated that AM1 and DFT calculations were close to experimental values and to each other, while $a b$ initio values were twice higher than experimental ones. So our choice of calculation method was based on simplicity and reliability. For comparison we also did semiempirical PM3 calculations. As mentioned above, our objects of interest are TNF and $\mathrm{Cz}$ molecules as electron acceptor and donor respectively. Their equilibrium AM1 structures are presented in Figs. 3 and 4 both for neutral and ionized forms.

PM3 structures were calculated too, but not presented here.

AM1 and PM3 calculated energy values for all structures are presented in Table 1. Calculation of inner reorganization energies $\lambda_{\mathrm{i}}$, free energies of CT reac-

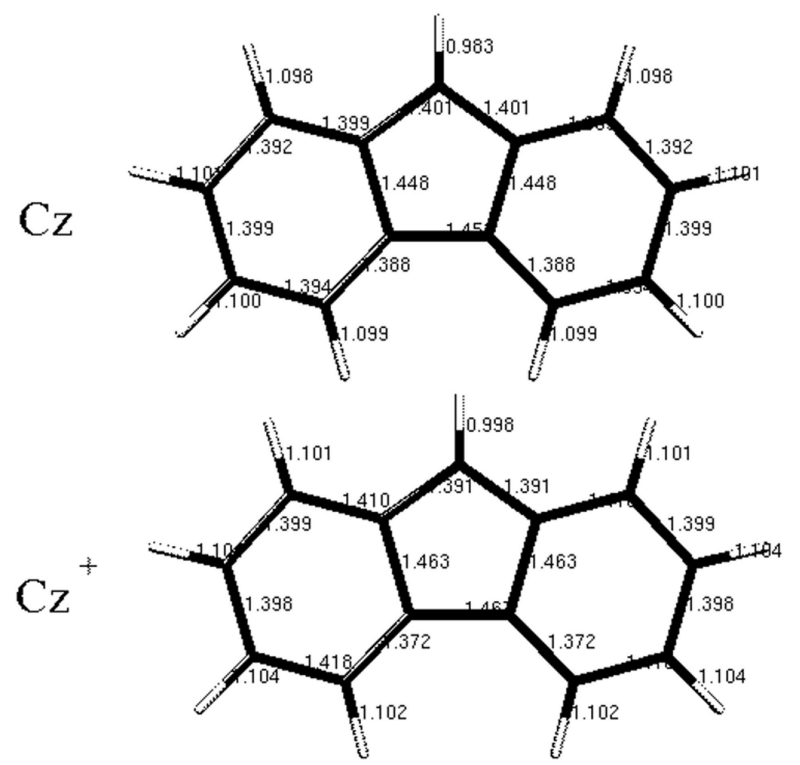

Fig. 3. Carbazole neutral $(\mathrm{Cz})$ and cationic $\left(\mathrm{Cz}^{+}\right)$equilibrium structures optimized using AM1 method. Bond lengths are presented in $\AA$.
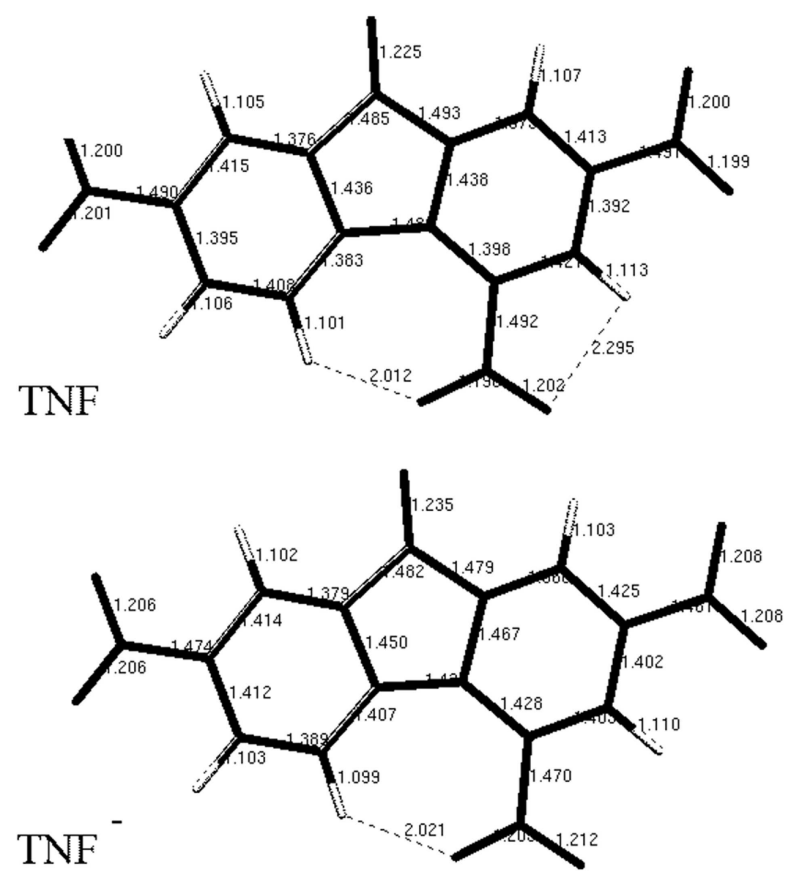

Fig. 4. 2,4,7-trinitrofluorenone neutral (TNF) and anionic $\left(\mathrm{TNF}^{-}\right)$ equilibrium structures optimized using AM1 method. Bond lengths are presented in $\AA$.

tion $\Delta G^{0}$, vertical $I_{\mathrm{g}}^{\mathrm{v}}$ and adiabatic $I_{\mathrm{g}}^{\mathrm{a}}$ ionization potentials, vertical $A_{\mathrm{g}}^{\mathrm{v}}$ and adiabatic $A_{\mathrm{g}}^{\mathrm{a}}$ affinities of electron are presented in Table 2. Calculation of $I_{\mathrm{g}}^{\mathrm{v}}, I_{\mathrm{g}}^{\mathrm{a}}$, $A_{\mathrm{g}}^{\mathrm{v}}$, and $A_{\mathrm{g}}^{\mathrm{a}}$ was based on definition presented in [3]. $\Delta G^{0}$ value corresponds to pure quantum chemical calculation without external or Coulomb fields. For CT cross-reaction going in the reverse direction (than presented in Table 2) the sign for $\Delta G^{0}$ should be changed 
Table 2. Calculated values of reorganization energies, free energies, ionization potentials, and electron affinities. Units are presented in hartrees (a. u.) and electronvolts (in parentheses). Nonzero $\Delta G^{0}$ value is presented for $D^{+}+A^{-} \rightarrow D+A$ process (recombination) in $\mathrm{Cz}-\mathrm{TNF}$ pair. For a reverse process (initial charge separation) the sign of it should be changed to opposite.

\begin{tabular}{cccc}
\hline Compound & Value & AM1 & PM3 \\
\hline \multirow{2}{*}{$\mathrm{Cz}$} & $\Delta G^{0}$ & 0 & 0 \\
\cline { 2 - 4 } & $\lambda_{D}$ & $\begin{array}{c}0.00555 \\
(0.15)\end{array}$ & $\begin{array}{c}0.01768 \\
(0.451)\end{array}$ \\
\cline { 2 - 4 } & $I_{\mathrm{g}}^{\mathrm{v}}$ & 0.28063 & 0.28882 \\
\cline { 2 - 4 } & $I_{\mathrm{g}}^{\mathrm{a}}$ & 0.27789 & 0.27567 \\
\hline TNF & $\Delta G^{0}$ & 0 & 0 \\
\cline { 2 - 4 } & $\lambda_{A}$ & $\begin{array}{c}0.01431 \\
(0.389)\end{array}$ & $\begin{array}{c}0.020 \\
(0.549)\end{array}$ \\
\cline { 2 - 4 } & $A_{\mathrm{g}}^{\mathrm{v}}$ & 0.13224 & 0.12864 \\
\cline { 2 - 4 } $\mathrm{Cz}-\mathrm{TNF}$ & $A_{\mathrm{g}}^{\mathrm{a}}$ & 0.13934 & 0.13877 \\
& $\Delta G^{0}$ & -0.13855 & -0.1369 \\
& $\lambda_{\mathrm{i}}$ & $(-3.77)$ & $(-3.725)$ \\
\hline \multirow{2}{*}{} & & $(0.27)$ & $(0.515)$ \\
\hline
\end{tabular}

to opposite. Thus positive free energy value indicates that initial charge separation (thermalization) is impossible without photoexcitation of TNF molecule. For photoexcited state, photon energy should be subtracted from the positive $\Delta G^{0}$ value. Also, external electric field and Coulomb field corrections should be applied for free energy values in a case of presence of such fields. We can see that values of free energies, ionization potentials, and electron affinities are close to each other for both AM1 and PM3 calculations. Meanwhile, reorganization energy values are higher in the case of PM3 calculation. We can see from [10] that these $\lambda_{\mathrm{i}}$ numerical values lay down into region where photogeneration proceeds efficiently, especially in the case of AM1 calculations. This supports the validity of our calculations because photogeneration in $\mathrm{Cz}$ compounds containing TNF really goes very effectively. It would be interesting to compare our calculated values with experimental data or with other calculations, but we did not find such material. There are a lot of experimental data on hole mobility measurements in compounds containing carbazole and dependences of such mobility on temperature and external electric field. Possibly the reorganization energy could be extracted from such data, but a more thorough examination of this question is left for the future work. In [10] it was mentioned that $\lambda_{\mathrm{i}}=0.15 \mathrm{eV}$ for carbazole leads to typical mobility value observed in organic semiconductors. Our AM1 calculated value of $\lambda_{\mathrm{i}}$ is exactly the same (see Table 2), so it is very reasonable. It may be noted that authors of paper [13] while dealing with aromatic heterocyclic compounds based on one and two benzene rings have obtained similar values for inner reorganization energies.

Another interesting question left for future work is the interaction matrix element calculation for electron or hole transport using quantum chemical methods.

Summarizing, it may be said that quantum chemical calculations have been carried out in order to obtain numerical values of inner reorganization energy for CT reactions taking part in carbazole compounds containing trinitrofluorenone and they give reasonable values.

\section{References}

[1] R.A. Marcus, Electron transfer reactions in chemistry. Theory and experiment, Rev. Mod. Phys. 65, 599-610 (1993) (and citation therein).

[2] G. Ramos, T. Belenquer, and D. Levy, A highly photoconductive poly(vinylcarbazole)/2,4,7-trinitro9-fluorenone sol-gel material that follows a classical charge-generation model, J. Phys. Chem. B 110, 24780-24785 (2006).

[3] M. Pope and Ch.E. Swenberg, Electronic Processes in Organic Crystals (Oxford University Press, New York, 1982).

[4] E.A. Silinsh, M. Kurik, and V. Capek, Electronic Processes in Organic Molecular Crystals (Zinatne, Riga 1988) [in Russian].

[5] H. Sano and A. Mazumder, Model of thermalization of quasifree electrons in high-mobility liquids and its relationship with electron mobility, J. Chem. Phys. 66, 689-698 (1977).

[6] E.A. Silinsh and A.J. Jurgis, Photogenerated geminate charge-pair separation mechanisms in pentacene crystals, Chem. Phys. 94, 77-90 (1985).

[7] Š. Kudžmauskas, Photogeneration of geminate electron-hole pairs in quasi-one-dimensional aggregates. Theory of the tunneling in thermalization stage, Lithuanian Phys. J. 31, 511-521 (1991).

[8] L. Onsager, Initial recombination of ions, Phys. Rev. 54, 554-557 (1938).

[9] Š. Kudžmauskas, Charge carrier hopping transport and generation in quasi-onedimensional disordered molecular structures, Lietuvos Fizikos Rinkinys [Sov. Phys. Collection] 26, 676-680 (1986).

[10] Š. Kudžmauskas and G. Vektaris, Theory of charge photogeneration in quasione-dimensional structures, Lithuanian Phys. J. 35, 183-189 (1995).

[11] S. Jakobsen, K.V. Mikkelsen, and S.U. Pedersen, Calculations of intramolecular reorganization energies for electron-transfer reactions involving organic systems, J. Phys. Chem. 100, 7411-7417 (1996). 
[12] S.F. Nelsen, S.C. Blackstock, and Y. Kim, Estimation of inner shell Marcus terms for amino nitrogen compounds by molecular orbital calculations, J. Am. Chem. Soc. 109, 677-682 (1987).

[13] Sh. Ma, Xia. Zhang, H. Xu, Xin. Zhang, and Q. Zhang, AM1 and $a b$ initio studies on the internal reorganization energy of self-exchange electron transfer reaction of several quinone derivatives, Chin. Sci. Bull. 46, 1242-1250 (2001).

[14] R.A. Marcus, Schrödinger equation for strongly interacting electron-transfer systems, J. Phys. Chem. 96,
1753-1757 (1992).

[15] M.W. Schmidt, K.K. Baldridge, J.A. Boatz, S.T. Elbert, M.S. Gordon, J.H. Jensen, S. Koseki, N. Matsunaga, K.A. Nguyen, S. Su, T.L. Windus, M. Dupuis, and J.A. Montgomery, General atomic and molecular electronic structure system, J. Comput. Chem. 14, 1347-1363 (1993)

[16] P. Flukiger, H.P. Luthi, S. Portmenn, and J. Weber, MOLEKEL 4.0, Swiss Center for Scientific Computing (Manno, Switzerland, 2000).

\title{
KRŪVININKO PERNAŠOS REORGANIZACIJOS ENERGIJOS KARBAZOLO JUNGINYJE, TURINČIAME TRINITROFLUORENONO
}

\author{
G. Vektaris ${ }^{\mathrm{a}}, \mathrm{A}$. Vektariené ${ }^{\mathrm{a}, \mathrm{b}}$

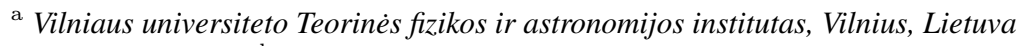 \\ ${ }^{\mathrm{b}}$ Biochemijos institutas, Vilnius, Lietuva
}

\section{Santrauka}

Kvantinès chemijos metodais apskaičiuotas krūvininkų pernašą aprašantis parametras - vidinès reorganizacijos energija - karbazolo medžiagose, turinčiose trinitrofluorenono. Buvo optimizuoti karbazolo ir trinitrofluorenono neutralių, katijoninių (karbazolo) ir anijoniniu (trinitrofluorenono) molekuliu geometriniai pavidalai. Gauti molekuliu geometriniai pavidalai buvo naudojami apskaičiuoti ju energijai neutraliose ir joninèse formose. Nelsen'o metodu buvo surasta skylutès pernašą karbazole aprašančios vidinès reorganizacijos energijos vertè. Elektrono šuoliui nuo karbazolo ant trinitrofluorenono ir atgal aprašyti buvo naudojamas Marcus'o sąryšis. Pastarajai krūvininko pernašos reakcijai taip pat apskaičiuota ir reakcijos laisvoji energija. Aptartas gautu rezultatụ tinkamumas krūvininkų atskyrimo reakcijoms karbazolo junginiuose, naudojamuose elektrografiniuose sluoksniuose. 